\section{JANET GOODWIN} RECOGNISED FOR HER OUTSTANDING CONTRIBUTION

Janet Goodwin has been awarded an

Honorary Fellowship of the Faculty of

General Dental Practice (UK) for her commitment to the dental profession. Her service includes working in general practice, in community dental services, in hospital and in education. She has represented DCPs at the Faculty over many years.

Janet is an affiliate of FGDP(UK) and has long served as a representative of the wider dental team. She is a dedicated observer on the Board and a contributor to many standing committees, as well as Chair of the DCP Committee. With a long career in dentistry, Janet currently consults on management and educational projects and she holds an honours degree in business management.

A long time supporter of BADN, Janet received her 25+ years membership brooch from President Hazel Coey at the 2018 National Dental Nursing Conference. She is also a recipient of the BADN Outstanding Contribution to Dental Nursing Award and a BADN Fellow.

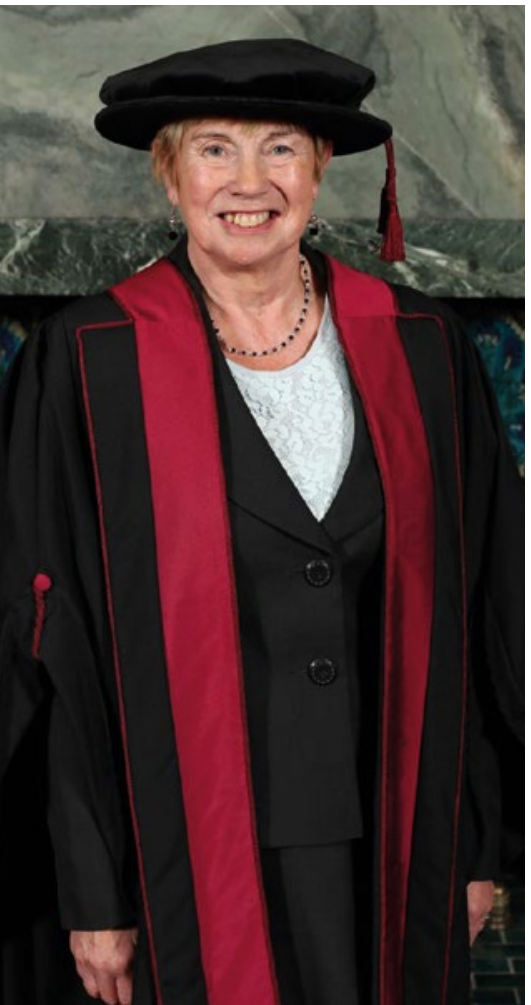

BADN President Hazel Coey said 'We are delighted that Janet's contribution to dental nursing, and to dentistry in general, has been recognised by the Faculty of General Dental Practice (UK) and congratulate Janet on her Honorary Fellowship.'
NEARLY HALF OF BREAKFAST CEREALS STILL CONTAIN TOO MUCH SUGAR

Breakfast cereals still contain 'unacceptable' amounts of sugar and supermarkets' ownbrand products are the worst offenders. This is according to the campaign group Action on Sugar which followed up the amount of sugar in cereal after the NHS urged manufacturers to reduce sugar in cereals or face a mandatory sugar tax like the one on soft drinks.

Action on Sugar found nearly half still contain large amounts of sugar, with a way to go for companies to meet Public Health England's target of cutting sugar content by 20 per cent. The worst offending cereal, Malt-O-Meal's Marshmallow Mateys, was found to be 40 per cent sugar. Other cereals containing more than $30 \mathrm{~g}$ per 100g included Morrisons Choco Pillows (36.1g), Sainsbury's Frosted Flakes (34g) and Morrisons Choco Crackles (32.1g). Supermarket own-brand cereals dominated the 20 most sugar-filled options, taking 18 of the places. The campaign group now say it is 'immoral' to have colourful cartoon packaging aimed at children, and are now calling for it to be banned.

\title{
DCP EMPOWERMENT IN WALES
}

Team working among dental professionals in Wales is being supported with a resource launched by Health Education and Improvement Wales (HEIW). The Skills Optimiser Self-Evaluation Tool (SOSET) encourages dental teams to put teamwork at the forefront of their approach to delivering effective oral healthcare.

Research suggests that $73 \%$ of treatment in general dental practices could be carried out by DCPs - dental nurses, hygienists, therapists, and technicians - freeing up dentists' time to provide advanced care to patients with more complex needs. The SOSET matrix is a document designed to be introduced to dental practices by an HEIW Quality Improvement Educator. The QI educator involves the whole team in a discussion. SOSET is designed to encourage the attainment of goals, better communication through self-reflection and to help teams find gaps where improvements can be made.
HEIW was established on 1 October 2018. It is a special health authority within NHS Wales which amalgamated three key organisations for health: the Wales Deanery; NHS Wales's Workforce Education and Development Services (WEDS); and the Wales Centre for Pharmacy Professional Education (WCPPE).

Sitting alongside health boards and trusts, HEIW has a leading role in the education, training, development, and shaping of the healthcare workforce in Wales. Its key functions include education and training, workforce development and modernisation, leadership development, strategic workforce planning, workforce intelligence, careers, and widening access.

SOSET's approach of delegation and maximising skills within the team fits in with the Welsh Government's ambitions for prudent healthcare, giving patients more time to see the appropriate dentist or DCP.

Kathryn Marshall, Quality Improvement
Educator at HEIW, said: 'Making sure that dental team members (other than dentists) are able to work to their maximum skill level frees up clinical capacity elsewhere in the team.

'Dental practitioners will have more time and availability to improve patient access to other treatment needs such as restorative, endodontics, and paediatric dentistry. Patients will benefit from experiencing a step up in prevention, making use of a dental service that is fit for purpose for future generations, and care from a skilled and motivated dental team.' Further information can be found at https://heiw.nhs.wales/.

\section{References}

1. Health Education and Improvement Wales. Skills Optimiser Self-Evaluation Tool (SOSET). https://dental. walesdeanery.org/quality-improvement/ soset-\%E2\%80\%93-skills-optimiser-tool. (accessed March 2019). 